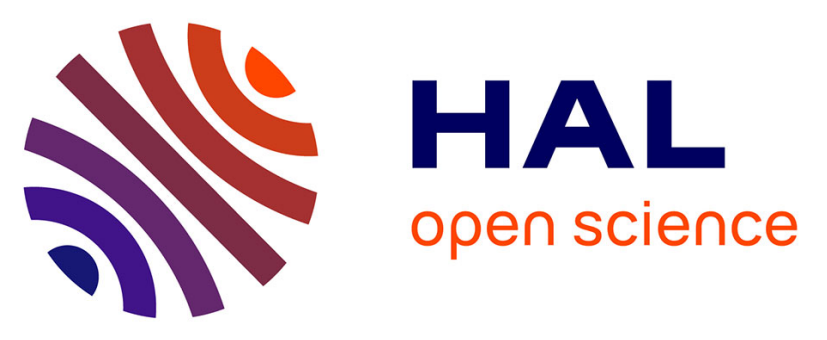

\title{
The expression of nicotinamide N-methyltransferas increases ATP synthesis and protects SH-SY5Y neuroblastoma cells against the toxicity of complex I inhibitors
}

Richard B Parsons, Shylesh Aravindan, Anusha Kadampeswaran, Emily A. Evans, Kanwaljeet K. Sandhu, Elizabeth Levy, Martin G Thomas, Brian M Austen, David B Ramsden

\section{- To cite this version:}

Richard B Parsons, Shylesh Aravindan, Anusha Kadampeswaran, Emily A. Evans, Kanwaljeet K. Sandhu, et al.. The expression of nicotinamide N-methyltransferas increases ATP synthesis and protects SH-SY5Y neuroblastoma cells against the toxicity of complex I inhibitors. Biochemical Journal, 2011, 436 (1), pp.145-155. 10.1042/BJ20101685 . hal-00591707

\section{HAL Id: hal-00591707 https://hal.science/hal-00591707}

Submitted on 10 May 2011

HAL is a multi-disciplinary open access archive for the deposit and dissemination of scientific research documents, whether they are published or not. The documents may come from teaching and research institutions in France or abroad, or from public or private research centers.
L'archive ouverte pluridisciplinaire HAL, est destinée au dépôt et à la diffusion de documents scientifiques de niveau recherche, publiés ou non, émanant des établissements d'enseignement et de recherche français ou étrangers, des laboratoires publics ou privés. 
Parsons et al. NNMT expression is cytoprotective via Complex I

THE EXPRESSION OF NICOTINAMIDE $N$-METHYLTRANSFERASE INCREASES ATP SYNTHESIS AND PROTECTS SH-SY5Y NEUROBLASTOMA CELLS AGAINST THE TOXICITY OF COMPLEX I INHIBITORS

Richard B. Parsons*, Shylesh Aravindan ${ }^{\dagger}$, Anusha Kadampeswaran ${ }^{\dagger}$, Emily A. Evans ${ }^{\dagger}$, Kanwaljeet K. Sandhu ${ }^{\dagger}$, Elizabeth R. Levy*, Martin G. Thomas*, Brian M. Austen ${ }^{\dagger}$ and David B. Ramsden

*King's College London, Institute of Pharmaceutical Science, 150 Stamford Street, London SE1 9NH, UK

$\dagger$ St. George's, University of London, Division of Basic Medical Sciences, Cranmer Terrace, London SW17 0RE, UK

The University of Birmingham, Department of Medicine, Edgbaston, Birmingham B15 2TH, UK

\section{Corresponding author:}

Dr. Richard B. Parsons, King's College London, Institute of Pharmaceutical Science, 150 Stamford Street, London SE1 9NH, UK

Tel: +44207848 4048

Fax: +44 2078484800

Email: richard.parsons@kcl.ac.uk

Running title: NNMT expression is cytoprotective via Complex I 
Parsons et al. NNMT expression is cytoprotective via Complex I

\begin{abstract}
Nicotinamide $N$-methyltransferase (NNMT, E.C. 2.1.1.1) catalyses the $N$-methylation of nicotinamide to 1-methylnicotinamide. NNMT expression is significantly elevated in a number of cancers, and we have previously demonstrated that NNMT expression is significantly increased in the brains of patients who have died of Parkinson's disease. To investigate the cellular effects of NNMT overexpression, we overexpressed NNMT in the SH-SY5Y cell-line, a tumour-derived human dopaminergic neuroblastoma cell-line with no endogenous expression of NNMT. NNMT expression significantly decreased SH-SY5Y cell death, which correlated with increased intracellular ATP content, ATP:ADP ratio, Complex I activity and a reduction in the degradation of the NDUFS3 subunit of Complex I. These effects were replicated by incubation of SH-SY5Y cells with 1-methylnicotinamide, suggesting that 1-methylnicotinamide mediates the cellular effects of NNMT. Both NNMT expression and 1-methylnicotinamide protected SH-SY5Y cells from the toxicity of the Complex I inhibitors MPP+ and rotenone by reversing their effects upon ATP synthesis, ATP:ADP ratio, Complex I activity and the NDUFS3 subunit. These results raise the possibility that the increase in NNMT expression that we observed in vivo may be a stress response of the cell to the underlying pathogenic process. Furthermore, these results also raise the possibility of using inhibitors of NNMT for the treatment of cancer.
\end{abstract}

Key words: Parkinson's disease, energy metabolism, cytoprotection, cancer, NDUFS3, $N$ methylation

\title{
Abbreviations:
}

CGC: cerebellar granule cells; CS: citrate synthase; CxI: Complex I; DC: dichloroindophenol; ECL: electrochemiluminescence detection; GAPDH: glyceraldehyde 3phosphate dehydrogenase; HRP: horseradish peroxidase; LDH: lactate dehydrogenase; MeN: 1-methylnicotinamide; NDUFS3: 30kDa subunit of Complex I; NNMT: Nicotinamide $\mathrm{N}$ methyltransferase; ORF: open reading frame; PD: Parkinson's disease; qPCR: real-time quantitative PCR; MPP+: 1-methyl-4-phenylpyridinium ion; ROS: reactive oxygen species; SirT-1: sirtuin-1. 
Parsons et al. NNMT expression is cytoprotective via Complex I

\section{INTRODUCTION}

The correct functioning of the mitochondria is essential for the production of ATP from NADH via oxidative phosphorylation within the inner mitochondrial membrane. Complex I (CxI) deficiency has been implicated in the pathogenesis of Parkinson's disease (PD) [1]. Nicotinamide, a form of vitamin B3, is the precursor for NAD+ synthesis [2], and plays a crucial role in cell survival and longevity [3]. Nicotinamide $N$-methyltransferase (NNMT, E.C. 2.1.1.1) catalyses the $N$-methylation of nicotinamide to 1 -methylnicotinamide (MeN) and is one of a family of three $N$-methyltransferases which share close sequence similarity [4]. NNMT is an S-adenosylmethionine-dependent enzyme with a molecular weight of $29 \mathrm{kDa}$ [5] which is present within a variety of tissues, the highest expression of which is in the liver [6]. NNMT expression in the brain is solely neuronal and there is a wide variation in the level of expression in the brain [6]. NNMT expression in both liver and brain follows a bimodal frequency distribution, with $25 \%$ of subjects in a high activity subgroup [6,7].

We have previously demonstrated increased expression of NNMT in the brains of patients who have died of PD, with a significant correlation between the level of a patient's NNMT expression and their disease duration [6,8], suggesting a causative effect in the pathogenesis of the disease. NNMT is also overexpressed in a number of cancers such as pancreatic [9], bladder [10], lung [11], gastrointestinal [12] and squamous cell carcinoma [13], and it has been suggested that NNMT expression can be used as a prognostic marker for cancer [13,14].

Studies using rat and bovine brain have shown that MeN is toxic to neurones of the substantia nigra, resulting in damage to the $30 \mathrm{kDa}$ subunit of CXI (henceforth referred to as NDUFS3) via the production of free radicals [15] and dopamine depletion [16]. In contrast, other studies using cerebellar granule cells (CGCs) show that MeN is neuroprotective against excitotoxins such as glutamate, although the authors described this neuroprotection as being weak at best $[17,18]$. MeN has been shown to be beneficial in conditions such as inflammation [19], hepatotoxicity [20] and thrombosis [19].

In this work we set out to investigate the cellular effects of NNMT expression using the human neuroblastoma-derived cell-line SH-SY5Y. Crucially, this cell-line has no endogenous expression of NNMT, therefore allowing us to study directly the effect of NNMT expression upon cell viability and to investigate whether the effects of NNMT are mediated by $\mathrm{MeN}$.

\section{METHODS}

Unless otherwise stated, all materials were obtained from Sigma (Poole, Dorset, UK) and were of the highest purity available.

\section{NNMT plasmid construction and stable mammalian expression}

SH-SY5Y human neuroblastoma cells were obtained from the European Collection of Animal Cell Cultures (Porton Down, UK) at passage number 16 and cultured as previously described [21]. All experiments were performed using undifferentiated cells of passage number $18-20$. The NNMT plasmid construct (pNNMT) was produced by ligating a cDNA encoding NNMT C-terminally fused to a V5 fusion tag into the pcDNA3.1 ${ }^{\mathrm{TM}}$-TOPOß mammalian expression vector (Invitrogen). The primer pair used was the following:

Forward: 5'-CACCATGGAATCAGGCTTCACCTCC-3'

Reverse: 5'-TCCTCTTCCAAGCAGGGGTCTGCTCAGCTTC-3'. 
Parsons et al. NNMT expression is cytoprotective via Complex I

pNNMT plasmid was transfected in SH-SY5Y cells using PolyPlus jetPEI transfection reagent (Autogen Bioclear, Wiltshire, UK). Stable transfectants were selected using geneticin $(250 \mu \mathrm{g} / \mathrm{mL}$, Invitrogen), and NNMT-V5 mRNA expression was confirmed using RT-PCR using the following primer pairs:

Forward: 5-TGGCCCCACTATCTATCAGC-3, Reverse: 5'-CCTCTTTCACAGCAGCCTCT-3'

$\beta$-actin was used as a loading control, detected using the following primer pair:

Forward: 5'-GGCATCCTCACCCTGAAGTA-3'

Reverse: 5'-GGGTGTTGAAGGTCTCAAA-3'

Recombinant NNMT-V5 expression was confirmed using SDS-PAGE Western blotting [6,8] using a combination of mouse-anti-V5 (1:2000, Abcam, Cambridge, UK) and anti-mouse IgG horse radish peroxidase (HRP) conjugate (1:2000). Protein loading was normalised using mouse-anti- $\beta$-actin $(1: 1000$, Autogen Bioclear). Detected bands were visualised using enhanced electrochemical luminescence detection (ECL) (GE Healthcare, Little Chalfont, UK). Enzyme activity of NNMT-V5 was confirmed using a previously-described radioassay [6]. NNMT activity was calculated and expressed as specific activity (nmol MeN produced/hour/mg protein) \pm S.D.. SH-SY5Y expressing NNMT was named S.NNMT.LP and used for all subsequent analyses.

\section{Cell death assays}

Cell death was measured using the Cytotoxicity Detection Kit (LDH)® (Roche Diagnostics, Lewes, UK) [21]. Cell death was calculated as percentage cell death \pm S.D.. Cellular apoptosis was measured by analysing caspase activation using the fluorescence-based Caspase-Glo ${ }^{\circledR}$ 3/7 assay kit (Promega, Southampton, UK) [21]; the assay relies upon the cleavage of a FRET-quenched substrate by Caspases $3 \& 7$ upon activation of apoptosis. Results were expressed as percentage change in apoptosis compared to untreated cells \pm S.D..

\section{Cell proliferation assay}

Cell proliferation was measured by assaying cell number using total cellular LDH content. Cells were plated at an equal density into 24-well plates and allowed to settle overnight. Baseline LDH content was obtained by lysing cells into the culture media by the addition of Triton X-100 (1\% v/v final concentration). Further samples were incubated for an additional 24 hours, after which cells were lysed, centrifuged at $14,000 \times \mathrm{x} g$ for 5 mins to precipitate particulate material, and LDH was measured in recovered supernatant as described above. Cell proliferation was calculated by dividing the LDH released from cells cultured for 24 hours by the baseline LDH value and expressed as proliferation ratio \pm S.D..

Intracellular indices of energy production

ATP and ADP concentrations were measured by bioluminescence using the luciferin/luciferase reaction-based ApoGlow ${ }^{\circledR}$ ATP:ADP assay kit (Lonza, Wokingham, UK) as per manufacturer's instructions. Results were expressed as pmoles/mg protein \pm S.D. and as ATP:ADP ratio \pm S.D..

Pyridine nucleotide concentrations were measured using the method of Queval and Noctor [22] with the use of $0.2 \mathrm{M} \mathrm{HCl}$ supplemented with $1 \%$ (v/v) Tween-20 instead of $0.2 \mathrm{mM} \mathrm{HCl}$ for the measurement of $\mathrm{NADH}$ and $0.2 \mathrm{M} \mathrm{NaOH}$ supplemented with $1 \%$ (v/v) Tween-20 
Parsons et al. NNMT expression is cytoprotective via Complex I

instead of $\mathrm{NaOH}$ for the measurement of NAD+. Absorbance was measured at $595 \mathrm{~nm}$ every 30 seconds for 10 mins at room temperature. Results were plotted and calculated as $\Delta \mathrm{A}_{595} / \mathrm{min}$ and converted to pmoles using a standard curve constructed from $0-40$ pmoles of appropriate pyridine nucleotide. Samples were corrected for volume and finally expressed as both $\mu \mathrm{M}$ pyridine nucleotide \pm S.D. and NAD+:NADH ratio \pm S.D..

\section{Mitochondrial membrane potential and oxygen consumption}

Mitochondrial membrane potential was measured using the fluorescence-based JC-1 Mitochondrial Membrane Potential Assay Kit (Cayman Chemical Company, Ann Abor, USA) in a 96-well plate format as per manufacturers instructions. Results were calculated and expressed as red:green fluorescence ratio \pm S.D.. Oxygen consumption in unstimulated cells and in the presence of oligomycin and 2,4-dinitrophenol was measured using a Clarke oxygen electrode using the method of Kwok et al. [23]. Results were calculated and expressed as the rate of oxygen consumption $/ \mathrm{min} / \mathrm{mg}$ protein \pm S.D..

\section{Complex I activity analysis}

Mitochondria were isolated from cells lysed into an ice-cold homogenisation buffer comprising $0.25 \mathrm{mM}$ sucrose, $10 \mathrm{mM}$ Tris and $1 \mathrm{mM}$ EDTA-Na, $\mathrm{pH}$ 7.4. Lysed membranes and nuclei were pelleted by centrifugation at $1,500 \mathrm{x} \mathrm{g}$ for $12 \mathrm{mins}$ at $4^{\circ} \mathrm{C}$. Mitochondria were isolated from the supernatant by centrifugation at $14,000 \times g$ for 12 mins at $6^{\circ} \mathrm{C}$ and resuspended in homogenisation buffer. CxI was measured in cell samples using the method of Janssen et al. [24] in a 96-well plate format. Rotenone-sensitive CxI activity was calculated and normalised for mitochondrial number using citrate synthase (CS) activity [24]. CS activity was calculated and used to normalise CxI activity, which is henceforth referred to simply as CxI activity. CxI activity was expressed as percentage of CxI activity observed in untreated SH-SY5Y cells \pm S.D...

\section{Real-time quantitative PCR analysis of NDUFS3 expression}

mRNA expression was quantified using real-time quantitative PCR (qPCR) using the Universal Probe Library as internal quantification probes (Roche). NDUFS3 expression was detected using primers and the appropriate Universal Probe (Roche, Welwyn Garden City, UK) as outlined in Table 1. qPCR was performed using an ABI Prism 7000 thermal cycler (Applied Biosystems) using FastStart Universal Probe Master Mix (Roche) using the following cycling conditions: $95^{\circ} \mathrm{C}$ for 10 mins, followed by 40 cycles of $95^{\circ}$ for 15 seconds and $60^{\circ} \mathrm{C}$ for 1 minute. The housekeeping genes $\beta$-actin and glyceraldehyde 3 -phosphate dehydrogenase (GAPDH) (Table 1) were used to normalise mRNA expression, and results were expressed as percentage expression compared to that observed in untreated SH-SY5Y cells \pm S.D.. The presence of single bands in each sample was subsequently confirmed using DNA gel electrophoresis.

\section{Western blotting analysis of NDUFS3 protein expression}

Protein samples were prepared, protein concentration quantified and subjected to Western blotting. NDUFS3 was detected using a combination of mouse-anti-NDUFS3 (1:2000, Invitrogen) at $4^{\circ} \mathrm{C}$ and rabbit-anti-mouse $\mathrm{IgG}, \mathrm{HRP}$ conjugate (1:5000). Membranes were stripped using Restore Western Stripping Reagent (Fisher Scientific) and re-probed using anti- $\beta$-actin. Images were digitally captured and band intensities were quantified using densitometric analysis using the GeneTools image analysis software (Syngene, Cambridge, UK) and normalised for $\beta$-actin expression. Results were calculated and expressed as ratio of the intensity observed in untreated SH-SY5Y cells \pm S.D., with each protein in untreated SHSY5Y cells having a ratio of 1 . 
Parsons et al. NNMT expression is cytoprotective via Complex I

\section{Experimental conditions}

For all experiments, undifferentiated SH-SY5Y cells cells were compared with undifferentiated SH-SY5Y cells incubated with various concentrations of MeN, 1-methyl-4phenylpyridinium ion (MPP+), rotenone and S.NNMT.LP cells as indicated in figure legends for 24 hours at $37^{\circ} \mathrm{C}$. The concentrations of $\mathrm{MeN}$ investigated are within the range used in other in vitro studies $[17,18,25,26]$ and are below the concentration reported to be neurotoxic by Fukushima and colleagues $(15-20 \mathrm{mM})[15,16]$. The effect of leupeptin upon NDUFS3 expression using Western blotting was investigated in undifferentiated SH-SY5Y cells incubated with $0,25,50$ and $100 \mu \mathrm{g} / \mathrm{mL}$ leupeptin for 24 hours at $37^{\circ} \mathrm{C}$.

\section{Statistical analysis}

All statistical analyses were performed using the Instat statistical package (GraphPad, San Jose, USA) and were performed using one-way ANOVA with post hoc Tukey comparisons. The exceptions to this were (1) the statistical analysis of qPCR data, (2) the comparison of NNMT activity in SH-SY5Y and S.NNMT.LP cells and (3) the effect of NNMT expression upon SH-SY5Y cell death and proliferation, for which a Student's t-test with Welch correction was used. P-values of less than 0.05 were taken as significant.

\section{RESULTS}

The expression of NNMT-V5 reduced SH-SY5Y cell death

S.NNMT.LP cells stably expressed both NNMT-V5 protein and NNMT mRNA, neither of which was present in the wild-type SH-SY5Y cell-line (Figure 1A). Calculation of the molecular weight for NNMT-V5 revealed a protein of $32 \mathrm{kDa}$, which taking into account the presence of the V5 epitope is in accord with the $29 \mathrm{kDa}$ size for NNMT [5,11]. NNMT-V5 was catalytically active in S.NNMT.LP cells at a level of activity similar to that observed in PD cerebellum [6]. Cell death was significantly lower in S.NNMT.LP cells compared to SHSY5Y cells (Figure 1B, bottom panel, $n=6$ ).

\section{1-Methylnicotinamide reduced SH-SY5Y cell death}

Incubation of SH-SY5Y cells with increasing concentrations of MeN reduced cell death (Figure $2 \mathrm{~A}, \mathrm{n}=6$ for all incubations). In order to discount the possibility that MeN may be interfering with the LDH assay, we also measured cellular apoptosis (Figure 2B). Cellular apoptosis also significantly decreased with increasing $\mathrm{MeN}$ concentration $(\mathrm{n}=6$ for all incubations).

It was possible that the apparent decrease in cell death observed may be due to increased cell proliferation. To investigate this, we compared the proliferation ratio of SH-SY5Y cells with both S.NNMT.LP cells and SH-SY5Y cells incubated with $1 \mathrm{mM}$ MeN. The proliferation ratios for SH-SY5Y and S.NNMT.LP cells were not significantly different $(1.61 \pm 0.17$, $\mathrm{p}=0.1446, \mathrm{n}=6)$. Incubation with $1 \mathrm{mM} \mathrm{MeN}$ also did not alter the proliferation ratio, being $1.53 \pm 0.016,1.47 \pm 0.007,1.45 \pm 0.018$ and $1.51 \pm 0.069$ for $0.1,0.25,0.5$ and $1 \mathrm{mM} \mathrm{MeN}$ respectively $(n=6$ for all incubations).

Both NNMT expression and incubation with $1 \mathrm{mM}$ 1-methylnicotinamide increased ATP production, the ATP:ADP ratio and CXI activity and reduced the NAD+:NADH ratio

In S.NNMT.LP cells the ATP:ADP ratio was approximately 4-fold higher compared with that in SH-SY5Y cells (Figure 3A, n=6), which was due to a significant increase in ATP concentration (Figure 3B) and a significant decrease in ADP concentration (Figure 3C). Likewise, the ATP:ADP ratio in SH-SY5Y cells incubated with $1 \mathrm{mM} \mathrm{MeN}$ also significantly 
Parsons et al. NNMT expression is cytoprotective via Complex I

increased compared to untreated SH-SY5Y cells (Figure 3A, n=6) as was the intracellular ATP concentration (Figure 3B), although ADP concentration was not significantly different (Figure 3C). There was a corresponding 4-fold increase in CxI activity in S.NNMT.LP cells compared to that observed in SH-SY5Y cells, along with a significant increase observed in SH-SY5Y cells incubated with $1 \mathrm{mM}$ MeN (Figure 3D, $\mathrm{n}=6$ ). Oxygen consumption increased significantly in SH-SY5Y cells incubated with $1 \mathrm{mM} \mathrm{MeN}$ and in S.NNMT.LP cells (Figure $3 \mathrm{E}, \mathrm{n}=4)$, which decreased in the presence of oligomycin and increased in the presence of 2,4-dinitrophenol (Figure 3F, n=4). The mitochondrial membrane potential did not significantly alter in either incubation condition, although incubation of SH-SY5Y with 1 $\mathrm{mM}$ 2,4-dinitrophenol significantly reduced the mitochondrial membrane potential (Figure $3 \mathrm{G}, \mathrm{n}=3$ ).

It is possible that these changes may have arisen from alterations in NADH availability. To assess this, we measured pyridine nucleotide concentrations and the NAD+:NADH ratio. The NAD+ concentration in S.NNMT.LP cells was significantly reduced compared to SH-SY5Y (Figure 4A, $n=4$ ), with a smaller yet still significant reduction in the NADH concentration in S.NNMT.LP cells (Figure 4B, n=4). Consequently, the NAD+:NADH ratio was significantly reduced in S.NNMT.LP cells compared to SH-SY5Y (Figure 4C). Incubating SH-SY5Y cells with $1 \mathrm{mM}$ MeN had no effect upon the NAD+ concentration compared to untreated SHSY5Y cells (Figure 4A, n=4), although there was a significant increase in the NADH concentration (Figure 4B, n=4). Consequently, the NAD+:NADH ratio was lower in $\mathrm{SH}-$ SY5Y cells incubated with $1 \mathrm{mM}$ MeN compared with that in untreated cells (Figure 4C, $\mathrm{n}=4)$.

NNMT expression and incubation with $1 \mathrm{mM} 1$-methylnicotinamide increased the expression of NDUFS3-immunoreactive proteins

We next investigated whether the effects we had observed were due to alterations in CxI subunit expression directly. In particular, we chose NDUFS3 because of the reported interaction between MeN and NDUFS3 [15,16]. NDUFS3 immunoreactivity was observed in three proteins of $39 \mathrm{kDa}, 45 \mathrm{kDa}$ and $50 \mathrm{kDa}$ (Figure $5 \mathrm{~A}$ ). The intensity of the $39 \mathrm{kDa}$ band was significantly higher than both the $45 \mathrm{kDa}$ and $50 \mathrm{kDa}$ bands. The expression of all three bands was increased in S.NNMT.LP cells compared to SH-SY5Y cells. The expression of all three bands also increased with increasing MeN concentration (Figure 5B), with peak expression observed at $0.5 \mathrm{mM} \mathrm{MeN}$ (Figure $5 \mathrm{C}$ top graph, $\mathrm{n}=4$ ). The increase in expression of the $45 \mathrm{kDa}$ and $50 \mathrm{kDa}$ bands was much more marked, with the maximal increase for both also observed after incubation with $0.5 \mathrm{mM} \mathrm{MeN}$ (Figure $5 \mathrm{C}$ bottom graph, $\mathrm{n}=4$ for both).

NDUFS3-immunoreactive proteins are subcellular localisation-specific

Having shown using SDS-PAGE Western blotting that NDUFS3 immunoreactivity was present in three bands, we decided to determine whether these immunoreactive proteins were subcellular localisation-specific using isolated mitochondria and post-mitochondrial supernatant (cytosol) (Figure 6). As previously observed, all three bands were present in SHSY5Y cell lysate, with the $39 \mathrm{kDa}$ band present solely in mitochondrial lysate and the 45 and $50 \mathrm{kDa}$ bands present solely in the post-mitochondrial supernatant. No other immunoreactive bands were observed in any of the subcellular fractions. Omission of primary antibody resulted in the detection of no immunoreactive bands.

NNMT expression and incubation with $1 \mathrm{mM}$ 1-methylnicotinamide did not alter NDUFS3 mRNA expression 
Parsons et al. NNMT expression is cytoprotective via Complex I

To determine whether these increases in NDUFS3 protein expression were due to increased protein synthesis arising from increased mRNA expression, we measured NDUFS3 mRNA expression in SH-SY5Y, S.NNMT.LP and SH-SY5Y cells incubated with 1mM MeN using qPCR. NDUFS3 mRNA expression was not significantly different in S.NNMT.LP cells compared to that observed in SH-SY5Y $(100 \pm 2.3 \%$ vs. $94.1 \pm 6.13 \%, \mathrm{p}=0.7830, \mathrm{n}=3)$. Likewise, NDUFS3 expression was not significantly altered in SH-SY5Y cells following incubation with $1 \mathrm{mM}$ MeN $(100 \pm 2.8 \%$ vs. $79.2 \pm 7.93 \%, \mathrm{p}=0.3302, \mathrm{n}=3)$.

\section{Inhibiting proteolysis increased NDUFS3 protein expression}

As the increases in NDUFS3 expression that we observed did not arise from an increase in mRNA expression, it is possible that they may have arisen from increased protein production or decreased protein catabolism. To investigate this, we inhibited lysosomal protein degradation using leupeptin [27]. All three NDUFS3-immunoreactive bands were observed in untreated SH-SY5Y cells, all of which increased significantly in expression with increasing leupeptin concentration (Figure 7A), with maximal increase observed in cells incubated with $50 \mu \mathrm{g} / \mathrm{mL}$ leupeptin (Figure 7B bottom panel, $\mathrm{n}=4$ ).

NNMT expression and incubation with $1 \mathrm{mM}$ 1-methylnicotinamide reduced the toxicity of the Complex I inhibitors MPP+ and rotenone

Having demonstrated that NNMT expression increased cell viability which coincided with the induction of CxI activity, and that this effect appeared to be mediated via a reduction in NDUFS3 degradation, we next decided to investigate whether NNMT may protect against the toxicity of the CxI inhibitors MPP+ and rotenone (Figure 8). To account for the lower cell death observed in untreated S.NNMT.LP cells compared to untreated SH-SY5Y (Figure 1B), the comparison of the toxicity of $0.5 \mathrm{mM} \mathrm{MPP}+$ and $0.4 \mu \mathrm{M}$ rotenone towards SH-SY5Y and S.NNMT.LP was expressed as the percentage increase in cell death compared to untreated cells. MPP+ was significantly toxic towards SH-SY5Y cells but not towards S.NNMT.LP cells. Rotenone was toxic towards both SH-SY5Y cells and S.NNMT.LP cells; however, rotenone was significantly more toxic towards SH-SY5Y cells than S.NNMT.LP cells $(n=6$ for all incubations).

Having demonstrated that NNMT expression protected against the toxicity of MPP+ and rotenone, it was decided to investigate whether MeN replicated these effects. Co-incubation of $0.5 \mathrm{mM}$ MPP+ and $0.4 \mu \mathrm{M}$ rotenone with $1 \mathrm{mM}$ MeN significantly reduced the toxicity of both CXI inhibitors towards SH-SY5Y cells, both of which were not significantly different to the degree of cell death observed in untreated SH-SY5Y cells (Figure 9A, n=6 for all incubations).

We next investigated whether the cytoprotective effects of MeN were mediated by changes in ATP and ADP concentrations, ATP:ADP ratio, CxI activity and NDUFS3 expression. Both $0.5 \mathrm{mM} \mathrm{MPP}+$ and $0.4 \mu \mathrm{M}$ rotenone reduced ATP concentration and increased ADP concentration which resulted in a decrease in the ATP:ADP ratio compared to that observed in untreated cells, which was reversed by co-incubation with $1 \mathrm{mM} \mathrm{MeN} \mathrm{(} \mathrm{m}=6$ for all incubations). Likewise, MPP+ and rotenone decreased CXI in SH-SY5Y cells, which coincubation with $1 \mathrm{mM} \mathrm{MeN}$ reversed back to levels which were not significantly different to those observed in untreated SH-SY5Y cells (Figure 9E, $n=6$ for both). Cellular oxygen consumption decreased significantly in response to MPP+ and rotenone, which was reversed by co-incubation with $1 \mathrm{mM} \mathrm{MeN}$ (Figure 9F, n=4 for all incubations). Oxygen consumption under all conditions decreased and increased in response to oligomycin and 2,4-dinitrophenol respectively (Figure 9G). The mitochondrial membrane potential also altered in a similar 
Parsons et al. NNMT expression is cytoprotective via Complex I

manner to that observed for oxygen consumption (Figure $9 \mathrm{H}, \mathrm{n}=3$ ). Both the $45 \mathrm{kDa}$ and 50 kDa NDUFS3-immunoreactive proteins were absent in SH-SY5Y cells incubated with MPP+ and rotenone, which was reversed by co-incubation with $1 \mathrm{mM} \mathrm{MeN} \mathrm{(Figure} \mathrm{9I).}$

\section{DISCUSSION}

NNMT expression reduced cell death by increasing CxI activity

A number of studies have shown that NNMT is overexpressed in a variety of diseases. None of these studies have addressed why, nor have they provided any mechanistic insights into why NNMT may have a role in disease progression. In this paper, we demonstrate that NNMT expression is involved in maintaining cell viability by increasing CxI activity, and that this appears to be mediated via the protection of NDUFS3 from degradation. Furthermore, we have shown that these effects arise due to the increased production of MeN, as incubation of cells with $1 \mathrm{mM} \mathrm{MeN}$ replicates all of the effects of NNMT upon cell viability. Finally, we demonstrate that NNMT and MeN are cytoprotective against the CxI inhibitors MPP+ and rotenone and that this is mediated via the maintenance of CxI activity arising from the protection of NDUFS3 from inhibitor-mediated damage.

Our previous studies using post mortem brain tissue demonstrated that NNMT levels are significantly higher in PD compared to non-PD patients. This, in tandem with an inverse correlation between disease duration and protein expression level, suggested a causative role for NNMT in the pathogenesis of PD [6,8]. This was supported by two studies which suggested that $\mathrm{MeN}$ is neurotoxic via the induction of free radicals similar in mechanism to that of paraquat, causing the destruction of NDUFS3 [15] and striatal dopamine depletion [16]. However, these studies had used MeN concentrations of $15-20 \mathrm{mM}$, which are significantly higher than found endogenously within the brain [28] and which have been shown to be significantly toxic towards macrophages [26]. Other studies have shown that $1 \mathrm{mM}$ is not toxic to primary CGCs, with toxicity only manifesting at concentrations of 100 $\mathrm{mM}$ [23]. Additionally, an intracellular MeN concentration of $500 \mu \mathrm{M}$ did not result in the death of hippocampal neurones in the rat brain in vivo [28].

Our original hypothesis was that overexpression of NNMT leads to a reduction in available nicotinamide for NADH synthesis, and that such a reduction in NADH synthesis may impinge upon the cell's ability to produce ATP, therefore leading to a reduction in cellular energy levels and thus reduce cell viability and/or reduce the ability of the cell to survive a subsequent cytotoxic challenge. One hurdle to this hypothesis was that NNMT overexpression is a common feature in many cancers, which do not demonstrate reduced cell viability but instead demonstrate increased proliferative capacity. To gain an insight into the potential consequences of NNMT expression that we have previously observed in patient brain samples [6,8], we ectopically expressed NNMT in a commonly used in vitro neuroblastoma cell-line which would allow us to investigate the mechanism underlying the effects of NNMT upon the cell. What makes this cell-line particularly useful is that it has no endogenous expression of NNMT, thus allowing us to directly quantify the effect that NNMT expression has upon the cell. It is also a tumour-derived cell-line, therefore it is also relevant to studying the role of NNMT in cancer.

Expression of NNMT in the SH-SY5Y cell-line significantly reduced cell death, which was replicated by incubation with $\mathrm{MeN}$. The decreases in cell death that we observed correlated with increases in ATP:ADP ratio and CxI activity. Various ATP:ADP ratios have been quoted in the literature for in vitro cell systems. The ATP:ADP ratio that we observed is similar to those reported for SH-SY5Y and other in vitro human cell-lines [29-31]. The 
Parsons et al. NNMT expression is cytoprotective via Complex I

increases in ATP concentration and ATP:ADP ratio coincided with similar increases in CXI activity, therefore we concluded that it was likely that NNMT and MeN increased cell viability via increased CXI activity, resulting in increased ATP concentration. Increases in ATP levels have been shown to rescue neurones from toxicity in several dopaminergic model systems [32-34], and is likely to be responsible for the decrease in cell death that we observed.

The effects of NNMT expression and 1-methylnicotinamide are mediated via Complex I Having identified that NNMT expression increased CxI activity, the next question we addressed was the mechanism by which this occurred. Alterations in NAD+:NADH ratio could conceivably alter electron flow through the mitochondrial respiratory chain, therefore significant increases in NADH availability may increase ATP synthesis. However, as nicotinamide is a precursor for pyridine nucleotide synthesis, we expected NADH and NAD+ concentrations to be significantly lower in the S.NNMT.LP cell-line than the parental SHSY5Y. As expected, we observed a decrease in the NAD+:NADH ratio which arose from a small decrease in NADH concentration and a very significant decrease in NAD+ concentration. Although global pyridine nucleotide synthesis is significantly reduced, as evidenced by the significantly lower NAD+ levels in S.NNMT.LP cells, the regeneration of NADH via the Krebs cycle is not compromised, as NADH concentrations were not sufficiently reduced to negatively impact upon ATP synthesis.

Another mechanism that we investigated was an interaction with the NDUFS3 subunit of CxI. CxI is a supercomplex of 45 subunits derived from both nuclear and mitochondrial DNA [35]. NDUFS3 is one of three nuclear DNA-encoded iron sulphur protein subunits of CxI, the incorporation of which occurs early in CxI assembly by the sequential association of NDUFS3 with other subunit proteins $[35,36]$. We investigated NDUFS3 because studies using rat brain has shown that $15-20 \mathrm{mM}$ MeN destroyed NDUFS3 via the production of free radicals in a mechanism similar to that of paraquat. There are a number of problems with this report. The concentrations of MeN used in the study were $10-100$-fold greater than the $1 \mathrm{mM}$ used in our study, which the majority of studies investigating the cellular effects of MeN have also used $[17,18,25,26]$. Also, their analysis of CxI subunit abundance was made using Coomassie brilliant blue staining of the mitochondrial fraction separated using SDSPAGE gel electrophoresis, which because of the number of proteins present in the sample and their inability to conclusively identify subunits without the use of specific antibodies, makes it difficult to identify the NDUFS3 subunit. Finally, the lack of a protein loading control such as $\beta$-actin makes it very difficult to quantify any changes that the authors observed. Using an antibody specific to NDUFS3, we observed that NDUFS3 immunoreactivity was present in a major protein of $39 \mathrm{kDa}$ plus two other bands of $45 \mathrm{kDa}$ and $50 \mathrm{kDa}$. It is likely that this 39 $\mathrm{kDa}$ protein is monomeric NDUFS3 and that the $45 \mathrm{kDa}$ and $50 \mathrm{kDa}$ proteins are NDUFS3 having either undergone post-translational modification or are tightly associated with other proteins as part of an assembly complex. One such candidate is prohibitin, a chaperonin shown to protect CxI subunits before assembly [37] which binds directly to NDUFS3 [38] The reason for the subcellular fraction specificity of these proteins is unclear, but it may be related to the localisation of the NDUFS3 gene to the nuclear DNA, resulting in the production of a cytosolic protein which undergoes translocation to the mitochondria.

Our use of a specific anti-NDUFS3 antibody also showed that the abundance of all three of these proteins increased with increasing MeN concentration. Although we have not fully characterised the identity of each of the NDUFS3-immunoreactive proteins, it is likely that they have functional relevance upon CxI activity as their increase in expression correlated 
Parsons et al. NNMT expression is cytoprotective via Complex I

with an increase in CXI activity and ATP synthesis. Furthermore, we were able to remove the 50 and $45 \mathrm{kDa}$ proteins by incubating SH-SY5Y cells with MPP+ and rotenone and subsequently reverse this by co-incubating with MeN. Most significantly, these changes correlated with alterations in ATP synthesis, ATP:ADP ratio and CxI ratio; in the absence of the $45 \mathrm{kDa}$ and $50 \mathrm{kDa}$ proteins, ADP concentration increased whereas ATP concentration, the ATP:ADP ratio and CxI decreased, which was reversed in the presence of both proteins. These changes suggest that these immunoreactive proteins are not an artefact of non-specific binding of the anti-NDUFS3 antibody, but represent true proteins which contain NDUFS3 whose expression are integral to the activity of CxI. Other reports have shown that NDUFS3 immunoreactivity is present in more than one protein [37-40]. Therefore, it is likely that the increase in the abundance of these proteins has functional relevance for CxI activity. This increase in protein expression arising from NNMT expression and MeN did not result from increased mRNA synthesis, but instead arose from a decrease in NDUFS3 degradation. This is evidenced by similar changes in NDUFS3 immunoreactive protein abundance in the presence of the lysosomal protease inhibitor leupeptin. Therefore, it is likely that NNMT increases CxI activity by reducing the degradation of the CxI subunit NDUFS3. As yet, it is unclear how NNMT and MeN reduce the degradation of NDUFS3. Possibilities include the direct inhibition of protein degradation itself, or the regulation of the expression of genes involved in protein transport or proteolysis. If the mechanism could be elucidated, it may serve as a possible target for drug development studies in PD.

NNMT expression and 1-methylnicotinamide protects against the toxicity of inhibitors of CxI Having identified that NNMT expression increases ATP:ADP ratio by maintaining CxI activity, mediated by a decrease in the degradation of NDUFS3, we wondered whether NNMT may protect against the toxicity of CXI inhibitors. When we exposed S.NNMT.LP cells to the CxI inhibitors MPP+ and rotenone, which were both significantly toxic towards SH-SY5Y cells, we observed that MPP+ was not significantly toxic, and rotenone were significantly less toxic towards S.NNMT.LP cells. This demonstrates that the reduction in pyridine nucleotide synthesis did not leave S.NNMT.LP cells susceptible to further neurotoxic challenge. Further experiments using 1-methylnicotinamide showed that this neuroprotection occurred via the protection of NDUFS3 from damage by MPP+ and rotenone, resulting in the maintenance of CxI activity and ATP:ADP ratio. This suggests that $\mathrm{MeN}$ is a naturally-occurring eytoprotective compound which, if replicated in vivo, raises the possibility of using MeN-based compounds as potential neuroprotective therapies for the treatment of PD.

Our in vitro data provide an insight into the potential cellular consequences of such an increase in NNMT expression in vivo and the mechanism by which it may occur. If our in vitro data were to be replicated in vivo, it raises the intriguing possibility that the significant increase in NNMT expression that we observed in PD patients $[6,8]$ is not contributing to the pathogenic process of PD, but is instead a stress response of the cell. Although no study has been made of MeN levels in PD patient brain, it is conceivable that the significant increase in NNMT expression observed may be an attempt to raise intracellular levels of MeN in order to increase CXI activity. Such a cytoprotective effect for NNMT is not without precedent. A recent study has shown that NNMT expression is induced in both the cirrhotic liver and experimental hepatitis as a hepatoprotective mechanism in response to the underlying pathogenic process, and that this is mediated by elevated MeN production [41]. Our data also suggests that the overexpression of NNMT in a variety of cancers may be a contributory factor to their accelerated growth, raising the possibility of using NNMT inhibitors for the treatment of cancer. 
Parsons et al. NNMT expression is cytoprotective via Complex I

In conclusion, the expression of NNMT protects the CxI subunit NDUFS3 from degradation, leading to an increase in ATP concentration and CxI activity. These effects are mediated via MeN, the product of nicotinamide $N$-methylation by NNMT. Furthermore, both NNMT expression and MeN protect undifferentiated SH-SY5Y cells from the toxicity of MPP+ and rotenone by maintaining CxI activity.

\section{FUNDING}

The authors would like to thank Parkinson's UK for funding this work [Grant ref 0505]. 
Parsons et al. NNMT expression is cytoprotective via Complex I

\section{REFERENCES}

1 Banerjee, R., Starkov, A. A., Beal, M. F. and Thomas, B. (2009) Mitochondrial dysfunction in the limelight of Parkinson's disease pathogenesis. Biochim. Biophys. Acta 1792, 651-963 2 Micheli, V., Simmonds, H. A., Sestini, S. and Ricci, C. (1990) Importance of nicotinamide as an NAD precursor in the human erythrocyte. Arch. Biochem. Biophys. 283, 40-45

3 Li, F., Chong, Z. Z. and Maise, K. (2006) Cell life versus cell longevity: the mysteries surrounding the NAD+ precursor nicotinamide. Curr. Med. Chem. 13, 883-895

4 Thompson, M. A., Moon, E., Kim, U. J., Sicilliano, M. J. ans Weilshilboum, R. M. (1999) Human indoethylamine N-methyltransferase: cDNA cloning and expression, gene cloning, and chromosomal localisation. Genomics 61, 285-297

5 Aksoy, S., Szumlanski, C. L. and Weinshilboum, R. M. (1994) Human liver nicotinamide $\mathrm{N}$-methyltransferase. cDNA cloning, expression, and biochemical characterization. J. Biol. Chem. 269, 14835-14840

6 Parsons, R. B., Smith, M. L., Williams, A. C., Waring, R. H. and Ramsden, D. B. (2002) Expression of nicotinamide N-methyltransferase (E.C. 2.1.1.1) in the Parkinsonian brain. J. Neurol. Exper. Neurol. 61, 111-124

7 Smith, M. L., Burnett, D., Bennett, P., Waring, R. H., Brown, H. M., Williams, A. C. and Ramsden, D. B. (1998) A direct correlation between nicotinamide N-methyltransferase activity and protein levels in human liver cytosol. Biochim. Biophys. Acta 1422, 238-244

8 Parsons, R. B., Smith, S. W., Waring, R. H., Williams, A. C. and Ramsden, D. B. (2003) High expression of nicotinamide N-methyltransferase in patients with idiopathic Parkinson's disease. Neurosci. Lett. 342, 13-16

9 Feldmann, G., Habbe, N., Dhara, S., Bisht, S., Alvarez, H., Fendrich, V., Beaty, R., Mullendore, M., Karikari, C., Bardeesy, N., Ouellette, M. M., Yu, W. and Maitra, A. (2008) Hedgehog inhibition prolongs survival in a genetically engineered mouse model of pancreatic cancer. Gut 57, 1420-1430

10 Kassem, H. S., Sangar, V., Cowan, R., Clark, N. and Margison, G. P. (2002) A potential role of heat shock proteins and nicotinamide $\mathrm{N}$-methyl transferase in predicting response to radiation in bladder cancer. Int. J. Cancer 101, 454-460

11 Tomida, M., Ohtake, H., Yokota, T., Kobayashi, Y. and Kurosumi, M. (2008) Stat3 upregulates expression of nicotinamide $\mathrm{N}$-methyltransferase in human cancer cells. J. Cancer Res. Clin. Oncol. 134, 551-559

12 Roessler, M., Rollinger, W., Palme, S., Hagmann, M. L., Berndt, P., Engel, A. M., Schneidinger, B., Pfeffer, M., Andres, H., Karl, J., Bodenmüller, H., Rüschoff, J., Henkel, T., Rohr, G., Rossol, S., Rösch, W., Langen, H., Zolg, W. and Tacke, M. (2005) Identification of nicotinamide $\mathrm{N}$-methyltransferase as a novel serum tumor marker for colorectal cancer. Clin. Cancer Res. 11, 6550-6557

13 Emanuelli, M., Santarelli, A., Sartini, D., Ciavarella, D., Rossi, V., Pozzi, V., Rubini, C. and Lo Muzio, L. (2010) Nicotinamide N-Methyltransferase upregulation correlates with tumour differentiation in oral squamous cell carcinoma. Histol. Histopathol. 25, 15-20

14 Kim, J., Hong, S. J., Lim, E. K., Yu, Y. S., Kim, S. W., Roh, J. H., Do, I. G., Joh, J. W. and Kim, D. S. (2009) Expression of nicotinamide N-methyltransferase in hepatocellular carcinoma is associated with poor prognosis. J. Exp. Clin. Cancer. Res. 28, 20

15 Fukushima, T., Kaetsu, A., Lim, H. and Moriyama, M. (2002) Possible role of 1methylnicotinamide in the pathogenesis of Parkinson's disease. Exp. Toxicol. Pathol. 53, 469-473

16 Fukushima, T., Tawara, T., Isobe, A., Hojo, N., Shiwaku, K. and Yamane, Y. (1995) Radical formation site of cerebral Complex I and Parkinson's disease. J. Neurosci. Res. 42, 385-390 
Parsons et al. NNMT expression is cytoprotective via Complex I

17 Slomka, M., Zieminska, E. and Lazarewicz, J. (2008) Nicotinamide and 1methylnicotinamide reduce homocysteine neurotoxicity in primary cultures of rat cerebellar granule cells. Acta Neurobiol. Exp. 68, 1-9

18 Slomka, M., Zieminska, E., Salinska, E. and Lazarewicz, J. W. (2008) Neuroprotective effects of nicotinamide and 1-methylnicotinamide in acute excitotoxicity in vitro. Folia Neuropathol. 46, 69-80

19 Gebicki, J., Sysa-Jedrzejowska, A., Adamus, J., Wozniacka, A., Rybak, M. and Zielonka, J. (2007) 1-methylnicotinamide (MNA), a primary metabolite of nicotinamide, exerts antithrombotic activity mediated by a cyclooxygenase-2/prostacyclin pathway. Br. J. Pharmacol. 152, 230-239

20 Pumpo, M. D., Sarnelli, G., Spinella, S., Budillon, G. and Cuomo, R. (2001) The metabolism of nicotinamide in human liver cirrhosis: a study on $\mathrm{N}$-methylnicotinamide and 2-pyridone-5-carboxamide production. Am. J. Gastroenterol. 96, 1183-1187

21 Matharu B., Gibson G., Parsons R., Huckerby T. N., Moore S. A., Cooper L. J., Millichamp R., Allsop D., Austen B.. (2009) Galantamine inhibits beta-amyloid aggregation and cytotoxicity. J. Neurol. Sci. 280, 49-58

22 Queval, G. and Noctor, G. (2007) A plate reader method for the measurement of NAD, NADP, glutathione, and ascorbate in tissue extracts: application to redox profiling during Arabidopsis rosette development. Analyt. Biochem. 363, 58-69

23 Kwok K. H., Ho P. W., Chu A. C., Ho J. W., Liu H. F., Yiu D. C., Chan K. H., Kung M. H., Ramsden D. B., Ho S. L. (2010) Mitochondrial UCP5 is neuroprotective by preserving mitochondrial membrane potential, ATP levels, and reducing oxidative stress in MPP+ and dopamine toxicity. Free Radic. Biol. Med. 49, 1023-1035

24 Janssen, A. J., Trijbels, F. J., Sengers, R. C., Smeitink, J. A., van den Heuvel, L. P., Wintjes, L. T., Stoltenborg-Hogenkamp, B. J. and Rodenburg, R. J. (2007) Spectrophotometric assay for Complex $I$ of the respiratory chain in tissue samples and cultured fibroblasts. Clin. Chem. 53, 729-734

25 Kuykendall, J. R., Cox, R. and Kinder, D. (2007) 1-Methylnicotinamide stimulates cell growth and inhibits hemoglobin synthesis in differentiating murine erythroleukaemia cells. Toxicol. In Vitro 21, 1656-1662

26 Biedron, R., Ciszek, M., Tokarczyk, M., Bobek, M., Kurnyta, M., Slominska, E. M., Smoleński, R. T. and Marcinkiewicz, J. (2008) 1-Methylnicotinamide and nicotinamide: two related anti-inflammatory agents that differentially affect the functions of activated macrophages. Arch. Immunol. Ther. Exp. 56, 127-134

27 Satoh, S., Yanagita, T., Maruta, T., Nemoto, T., Yoshikawa, N., Kobayashi, H., Tono, T. and Wada, A. (2008) Proteasomal degradation of IRS-2, but not IRS-1 by calcineurin inhibition: attenuation of insulin-like growth factor-I-induced GSK-3beta and ERK pathways in adrenal chromaffin cells. Neuropharmacology 55, 71-79

28 Erb, C., Seidel, A., Frank, H., Platt, K. L., Oesch, F. and Klein, J. (1999) Formation of Nmethylnicotinamide in the brain from a dihydropyridine-type prodrug: effect on brain choline. Biochem. Pharmacol. 15, 681-684

29 Rodriguez-Enriquez, S., Gallardo-Perez, J. C., Aviles-Salas, A., Marin-Hernandez, A., Carreno-Fuentes, L., Maldonado-Lagunas, V. and Moreno-Sanchez, R. (2008) Energy metabolism transition in multi-cellular human tumor spheroids. J. Cell Physiol. 216, 189-197 30 Storch, A., Burkhardt, K., Ludolph, A. C. and Schwarz, J. (2000) Protective effects of riluzole on dopamine neurons: involvement of oxidative stress and cellular energy metabolism. J. Neurochem. 75, 2259-2269

31 Chu, A. C-Y., Ho, P. W-L., Kwok, K. H-H., Ho, J. W-M., Chan, K-H., Liu, H-F., Kung, M. H-W., Ramsden, D. B., and Ho, S-L. (2009) Mitochondrial UCP4 attenuates MPP+- and 
Parsons et al. NNMT expression is cytoprotective via Complex I

dopamine-induced oxidative stress, mitochondrial depolarization, and ATP deficiency in neurons and is interlinked with UCP2 expression. Free Radic. Biol. Med. 46, 810-820

32 Lannuzel, A., Michel, P. P., Hoglinger, G. U., Champy, P., Jousset, A., Medja, F., Lombès, A., Darios, F., Gleye, C., Laurens, A., Hocquemiller, R., Hirsch, E. C. and Ruberg, M. (2003) The mitochondrial complex I inhibitor annonacin is toxic to mesencephalic dopaminergic neurons by impairment of energy metabolism. Neuroscience 121, 287-296

33 Wang, Y. M., Pu, P. and Le, W. D. (2007) ATP depletion is the major cause of MPP+ induced dopamine neuronal death and worm lethality in alpha-synuclein transgenic $\mathrm{C}$. elegans. Neurosci. Bull. 23, 329-335

34 Zieminska, E. and Lazarewicz, J. W. (2006) Excitotoxic neuronal injury in chronic homocysteine neurotoxicity studied in vitro: the role of NMDA and group I metabotropic glutamate receptors. Acta Neurobiol. Exp. 66, 301-309

35 Vogel, R. O., Dieteren, C. E., van den Heuvel, L. P., Willems, P. H., Smeitink, J. A., Koopman, W. J. and Nijtmans, L. G. (2007) Identification of mitochondrial Complex I assembly intermediates by tracing tagged NDUFS3 demonstrates the entry point of mitochondrial subunits. J. Biol. Chem. 282, 7582-7590

36 Ugalde, C., Vogel, R., Huijbens, R., van den Heuvel, B., Smeitink, J. and Nijtmans, L. (2004) Human mitochondrial complex I assembles through the combination of evolutionary conserved modules: a framework to interpret complex I deficiencies. Hum. Mol. Genet. 13, 2461-2472

37 Bourges, C. Ramus, B. Mousson de Camaret, R. Beugnot, C. Remacle, P. Cardol, G. Hofhaus, Issartel J. P. (2004) Structural organization of mitochondrial human complex I: role of the ND4 and ND5 mitochondria-encoded subunits and interaction with prohibitin, Biochem. J. 383 491-499

38 Park B, Young J, Nun N, Choe K-M, Jin B. K., Oh Y. J. (2010) Proteomic analysis of expression and protein interactions in a 6-hydroxydopamine-induced rat brain lesion model. Neurochem. Int. 57, 16-32

39 Huang G, Chen Y, Lu H, Cao X. (2007) Coupling mitochondrial respiratory chain to cell death: an essential role for mitochondrial complex I in the interferon-beta and retinoic acidinduced cancer cell death. Cell Death Differ. 14, 327-337

40 Martinvalet D, Dykxhoorn D. M. Ferrini R, Lieberman J. (2008) Granzyme A cleaves a mitochondrial complex I protein to initiate caspase-independent cell death. Cell 133, 681-692 41 Sternak, M., Khomich, T. I., Jakubowski, A., Szafarz, M., Szczepański, W., Białas, M., Stojak, M., Szymura-Oleksiak, J and Chłopicki, S. (2010) Nicotinamide N-methyltransferase (NNMT) and 1-methylnicotinamide (MNA) in experimental hepatitis induced by concanavalin A in the mouse. Pharmacol. Rep. 62, 483-493 
Biochemical Journal Immediate Publication. Published on 25 Feb 2011 as manuscript BJ20101685

Parsons et al. NNMT expression is cytoprotective via Complex I

Table 1. Primers and Universal Probes used for the analysis of mRNA expression using quantitative RT-PCR.

\begin{tabular}{|l|l|l|l|}
\hline Gene name & $\begin{array}{l}\text { Accession } \\
\text { number }\end{array}$ & Primer sequence & $\begin{array}{l}\text { UPL } \\
\text { number }\end{array}$ \\
\hline NDUFS3 & NM_004551.2 & F: ACTTTCCTCTATCTGGCTATGTTGA & 53 \\
\cline { 3 - 4 } & & R: GAACTCTTGGGCCAACTCC & \\
\hline \multirow{2}{*}{$\beta$-Actin } & NM_001101.3 & F: CCAACCGCGAGAAGATGA & 64 \\
\cline { 3 - 4 } & & R: CCAGAGGCGTACAGGGATAG & \\
\hline GAPDH & NM_002046.3 & F: AGCCACATCGCTCAGACAC & 60 \\
\cline { 3 - 4 } & & R: GCCCAATACGACCAAATCC & \\
\hline
\end{tabular}


Parsons et al. NNMT expression is cytoprotective via Complex I

Figure 1. The stable expression of nicotinamide $N$-methyltransferase significantly decreased SH-SY5Y cell death. NNMT was directionally inserted into the pcDNA3.1TOPO ${ }^{\circledR}$ mammalian-only expression vector and stably expressed in SH-SY5Y human neuroblastoma cells, producing the cell-line subsequently labelled S.NNMT.LP. (A) Top panel: detection of recombinant NNMT-V5. NNMT-V5 was detected by Western blotting using a combination of mouse-anti-V5 (1:2000) and anti-mouse IgG, HRP conjugate (1:2000). Equal protein loading was demonstrated using a combination of mouse-anti- $\beta$-actin (1:1000) and anti-mouse IgG, HRP conjugate (1:2000). Homogenate samples prepared from cells were loaded as indicated on the figure. The expression of $\beta$-actin and NNMT are as marked. Bottom panel: detection of NNMT mRNA. NNMT mRNA was detected using RTPCR using gene-specific primers as described in the text. Equal mRNA loading was demonstrated using $\beta$-actin. cDNA samples were loaded as indicated on the figure. The expression of $\beta$-actin and NNMT are as marked. $600=600 \mathrm{bp}$ marker. (B) Top panel: detection of NNMT enzyme activity. NNMT enzyme activity was detected using a previouslydescribed radioassay. Bottom panel: effect of NNMT expression upon cell death. Cell death was measured using LDH release.

Figure 2. 1-methylnicotinamide decreased SH-SY5Y cell death in a dose-dependent manner. (A) LDH release. SH-SY5Y cells were incubated with increasing concentrations of $\mathrm{MeN}$ for 24 hours, after which cell death was measured using LDH release. (B) Cellular apoptosis. SH-SY5Y cells were incubated with increasing concentrations of MeN for 24 hours, after which cellular apoptosis was measured using caspase $3 \& 7$ activation. For both panels, statistical analysis comprised the comparison of MeN-treated cells with untreated cells $(0 \mathrm{mM}): \mathrm{n} / \mathrm{s}=$ not significant, $*=\mathrm{p}<0.05$, $* *=\mathrm{p}<0.01$.

Figure 3. NNMT expression and 1-methylnicotinamide increased intracellular ATP:ADP and Complex I activity. (A) ATP:ADP ratio. SH-SY5Y, S.NNMT.LP and SHSY5Y cells incubated with $1 \mathrm{mM} \mathrm{MeN} \mathrm{for} 24$ hours were analysed for their intracellular ATP:ADP ratio. (B) ATP concentration. (C) ADP concentration. (D) Complex I activity. SHSY5Y, S.NNMT.LP and SH-SY5Y cells incubated with $1 \mathrm{mM}$ MeN for 24 hours were analysed for their CxI activity using a 96-well plate-based assay. (E) Oxygen consumption. Oxygen consumption was measured in whole unstimulated cells using a Clarke electrode. Oxygen consumption in SH-SY5Y cells was compared to SH-SY5Y cells incubated with 1 $\mathrm{mM} \mathrm{MeN}$ and S.NNMT.LP cells. (F) Typical oxygen consumption traces. Oxygen consumption was measured using in resting cells and in the presence of $5 \mu \mathrm{g} / \mathrm{mL}$ oligomycin and $1 \mathrm{mM}$ 2,4-dinitrophenol. (G) Mitochondrial membrane potential. Mitochondrial membrane potential was measured using JC-1 red:green ratio. Statistical analysis comprised the comparison of untreated SH-SY5Y with both SH-SY5Y incubated with $1 \mathrm{mM} \mathrm{MeN}$ and untreated S.NNMT.LP: $n / s=$ not significant, $*=p<0.05, * *=p<0.01 ; * * *=p<0.001$. For panels F \& G, 2,4-DNP = 2,4-dinitrophenol.

Figure 4. NNMT expression and 1-methylnicotinamide altered the NAD+:NADH ratio. The concentration of the pyridine nucleotides NAD+ and NADH were measured in SHSY5Y, S.NNMT.LP and SH-SY5Y cells incubated with $1 \mathrm{mM} \mathrm{MeN}$ for 24 hours using a 96well plate-based assay. (A) NAD+ concentration. (B) NADH concentration. (C) $N A D+: N A D H$ ratio. NAD+:NADH ratio was calculated using the intracellular NAD+ and NADH concentrations. Statistical analysis comprised the comparison of untreated SH-SY5Y with both SH-SY5Y incubated with $1 \mathrm{mM} \mathrm{MeN}$ and with untreated S.NNMT.LP: n/s = not significant, $*=\mathrm{p}<0.05, * *=\mathrm{p}<0.01 ; * * *=\mathrm{p}<0.001$. 
Parsons et al. NNMT expression is cytoprotective via Complex I

Figure 5. NNMT expression and 1-methylnicotinamide increased NDUFS3 expression in SH-SY5Y cells. (A) Comparison of NNMT immunoreactivity in SH-SY5Y and S.NNMT.LP cells. NDUFS3 was detected using Western blotting, using a combination of anti-mouseNDUFS3 (1:2000) and anti-mouse-IgG, HRP conjugate (1:5000). (B) Effect of 1methylnicotinamide upon NDUFS3 expression. SH-SY5Y cells were incubated with the concentrations of MeN indicated for 24 hours prior to Western blotting. (C) Densitometric analysis of $39 \mathrm{kDa}$ (top panel), $45 \mathrm{kDa}$ and $50 \mathrm{kDa}$ protein expression (bottom panel.) Bands intensities were measured using densitometry, normalised for $\beta$-actin expression (not shown) and expressed as a ratio of that observed in untreated cells \pm S.D.. For bottom panel, black bars $=45 \mathrm{kDa}$, white bars $=50 \mathrm{kDa}$. Statistical analysis was used to compare the expression of each immunoreactive NDUFS3 protein in MeN-treated cells with its expression in untreated cells $(0 \mathrm{mM}): \mathrm{n} / \mathrm{s}=$ not significant, $* * *=\mathrm{p}<0.001$.

Figure 6. The expression of NDUFS3-immunoreactive proteins are subcellular-specific. NDUFS3 subcellular expression was investigated in purified mitochondria and postmitochondrial supernatant using Western blotting. $1=$ whole cell supernatant; $2=$ purified mitochondria; $3=$ post-mitochondrial supernatant; $4=$ no primary antibody control.

Figure 7. The protease inhibitor leupeptin increased the abundance of NDUFS3immunoreactive proteins. (A) NDUFS3 immunoreactivity. SH-SY5Y cells were incubated with the concentrations of leupeptin indicated for 24 hours prior to Western blotting. NDUFS3 was observed in three bands of $39 \mathrm{kDa}, 45 \mathrm{kDa}$ and $50 \mathrm{kDa}$. (B) Densitometric analysis of $39 \mathrm{kDa}$ (top panel), $45 \mathrm{kDa}$ and $50 \mathrm{kDa}$ protein expression (bottom panel.) Bands intensities were measured using densitometry, normalised for $\beta$-actin expression (not shown) and expressed as a ratio of that observed in untreated cells \pm S.D.. For bottom panel, black bars $=45 \mathrm{kDa}$, white bars $=50 \mathrm{kDa}$. Statistical analysis was used to compare the expression of each immunoreactive NDUFS3 protein in leupeptin-treated cells with its expression in untreated cells $(0 \mathrm{mM}): \mathrm{n} / \mathrm{s}=$ not significant, $* * *=\mathrm{p}<0.001 .$.

Figure 8. NNMT expression significantly reduced the toxicity of the Complex I inhibitors MPP+ and rotenone. SH-SY5Y and S.NNMT.LP cells were incubated with 0.5 $\mathrm{mM} \mathrm{MPP}+$ and $0.4 \mu \mathrm{M}$ rotenone for 24 hours and cell death was subsequently measured using LDH release. Black bars $=$ SH-SY5Y, white bars $=$ S.NNMT.LP. Statistical analysis was used to compare (i) cell death in cells treated with $0.5 \mathrm{mM} \mathrm{MPP}+$ and $0.4 \mu \mathrm{M}$ rotenone with that observed in untreated SH-SY5Y cells (p-values above error bars) and (ii) cell death in S.NNMT.LP with that observed in SH-SY5Y in response to each incubation condition (pvalues above linking bars): $\mathrm{n} / \mathrm{s}=$ not significant, $* *=\mathrm{p}<0.01, * * *=\mathrm{p}<0.001$.

Figure 9. 1-methylnicotinamide reduced the toxicity of the Complex I inhibitors MPP+ and rotenone towards SH-SY5Y cells. SH-SY5Y cells were incubated with $0.5 \mathrm{mM} \mathrm{MPP+}$ and $0.4 \mu \mathrm{M}$ rotenone both in the presence and absence of $1 \mathrm{mM} \mathrm{MeN}$ for 24 hours. (A) Cell death. Cell death was measured using $\mathrm{LDH}$ release. (B) ATP:ADP ratio. ATP:ADP ratio was measured using a bioluminescence-based 96-well plate assay. (C) ATP concentration. (D) ADP concentration. (E) Complex I activity. (F) Oxygen consumption. Oxygen consumption was measured in untreated SH-SY5Y cells (black continuous line) and in SH-SY5Y cells incubated with $1 \mathrm{mM} \mathrm{MeN}$ (dashed and double-dotted line), $0.5 \mathrm{mM} \mathrm{MPP+} \mathrm{(long-dashed}$ line), $0.5 \mathrm{mM} \mathrm{MPP}++1 \mathrm{mM} \mathrm{MeN}$ (dashed and single-dotted line), $0.4 \mu \mathrm{M}$ rotenone (grey continuous line) and $0.2 \mu \mathrm{M}$ rotenone plus $1 \mathrm{mM} \mathrm{MeN}$ (small-dashed line). (G) Typical oxygen consumption traces. $(\mathrm{H})$ Mitochondrial membrane potential. Statistical analysis was used to compare (i) cells treated with $1 \mathrm{mM} \mathrm{MeN,} 0.5 \mathrm{mM} \mathrm{MPP}+$ and $0.4 \mu \mathrm{M}$ rotenone both 


\section{Parsons et al. NNMT expression is cytoprotective via Complex I}

in the presence and absence of $1 \mathrm{mM}$ MeN with untreated cells (p-values above error bars) and (ii) the effect of co-incubation with $1 \mathrm{mM}$ MeN compared to that observed in the absence of MeN for each incubation condition ( $\mathrm{p}$-values above linking bars): $\mathrm{n} / \mathrm{s}=$ not significant, $*=$ $\mathrm{p}<0.05, * *=\mathrm{p}<0.01, * * *=\mathrm{p}<0.001 ; 2,4-\mathrm{DNP}=2$,4-dinitrophenol. (I) NDUFS3 immunoreactivity. NDUFS3 was detected using Western blotting. $39=39 \mathrm{kDa}, 45=45 \mathrm{kDa}$, $50=50 \mathrm{kDa}, 1=$ untreated SH-SY5Y cells, $2=0.5 \mathrm{mM} \mathrm{MPP}+, 3=0.5 \mathrm{mM} \mathrm{MPP}+$ plus 1 $\mathrm{mM} \mathrm{MeN}, 4=0.4 \mu \mathrm{M}$ rotenone, $5=0.4 \mu \mathrm{M}$ rotenone plus $1 \mathrm{mM} \mathrm{MeN}$. 


\section{FIGURES.}
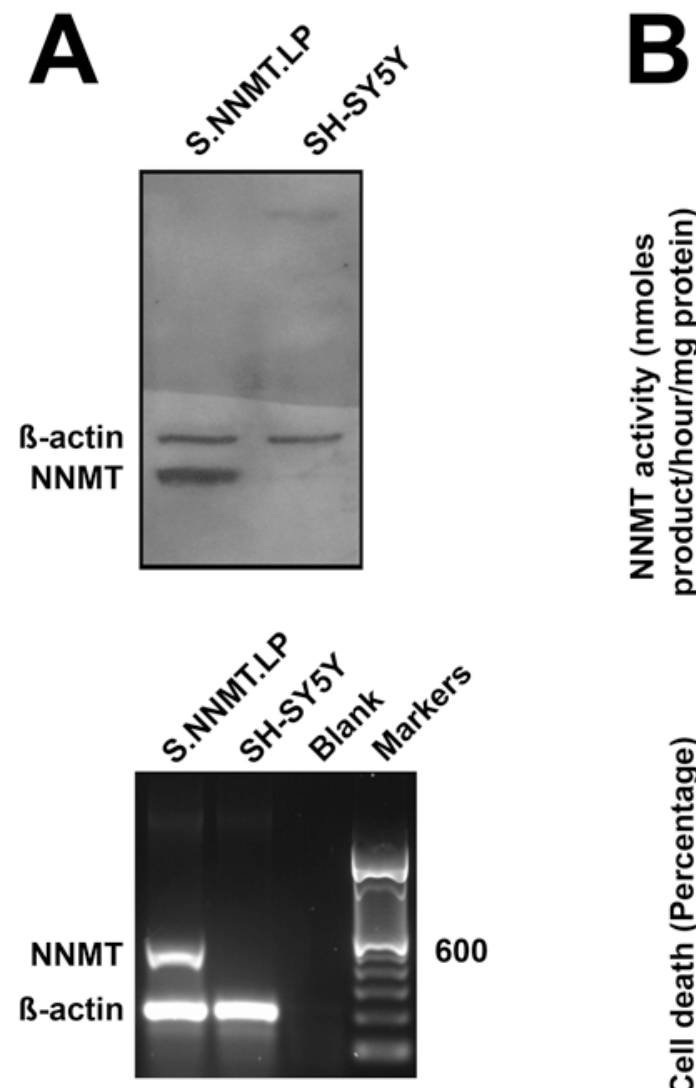

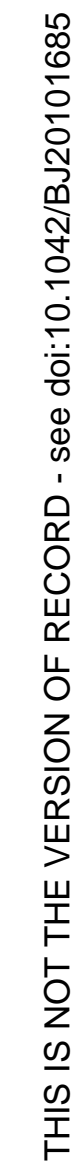

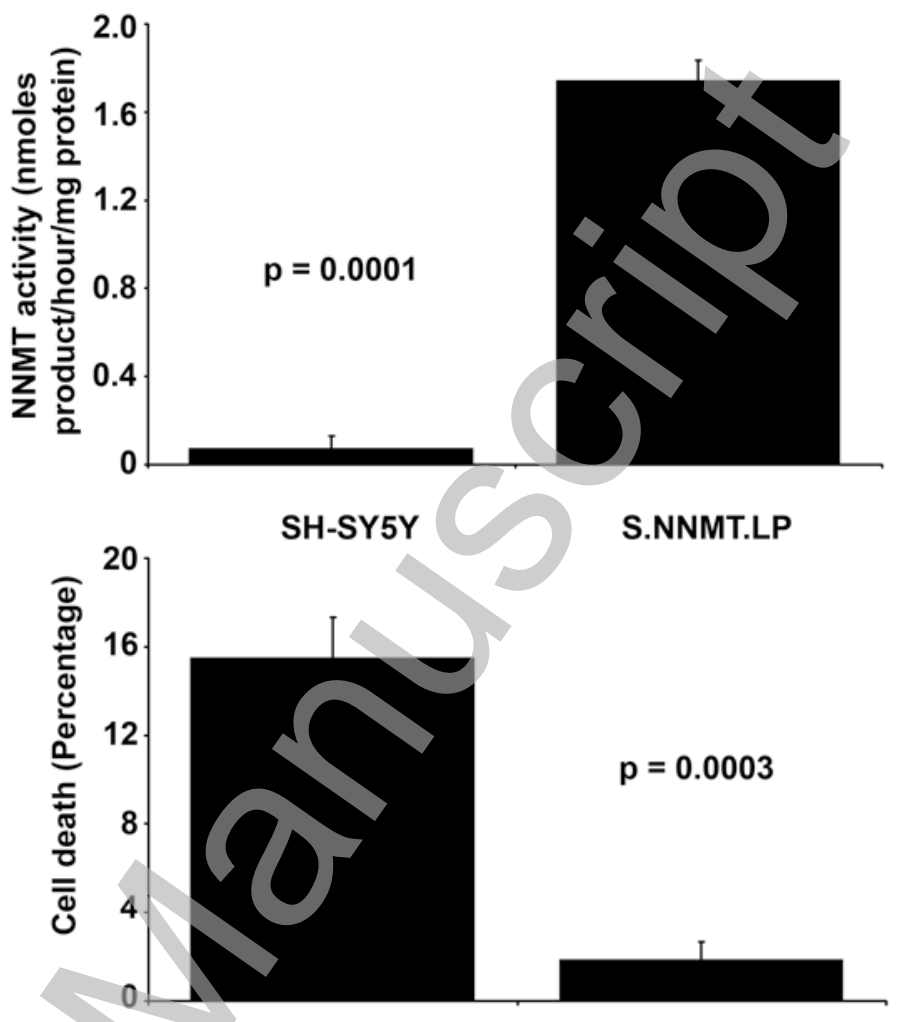

FIGURE 1 

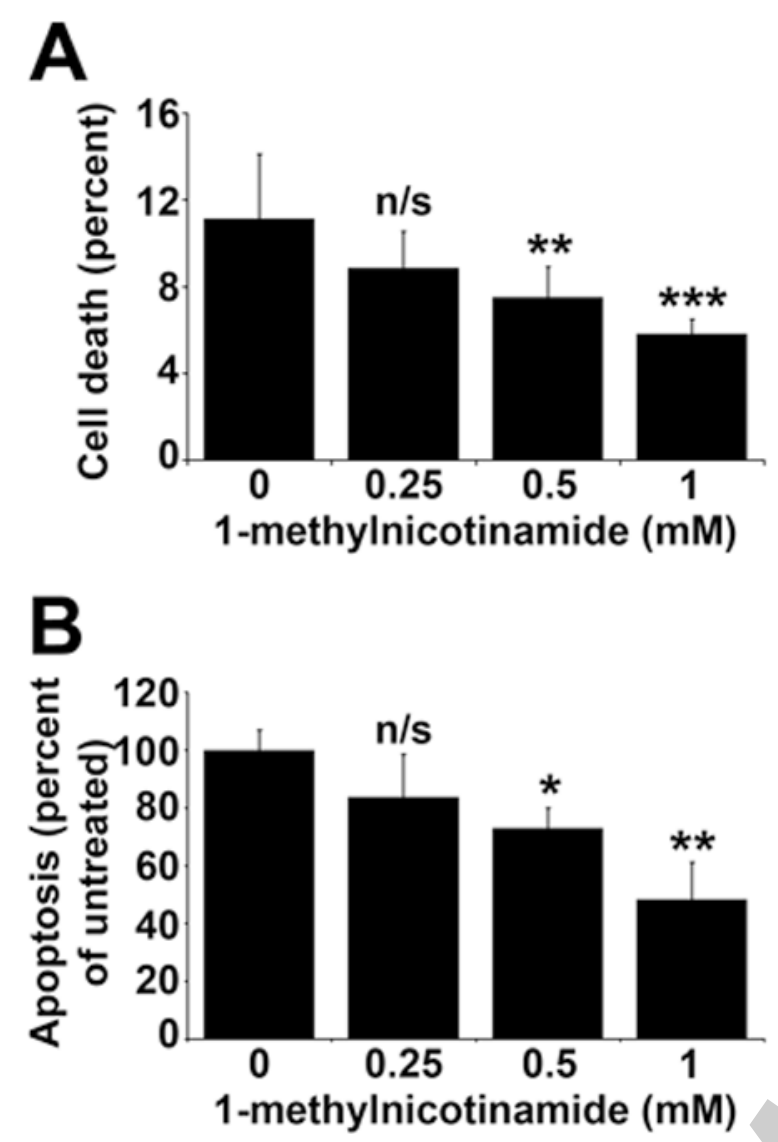

FIGURE 2 
Biochemical Journal Immediate Publication. Published on 25 Feb 2011 as manuscript BJ20101685

Parsons et al. NNMT expression is cytoprotective via Complex I

A

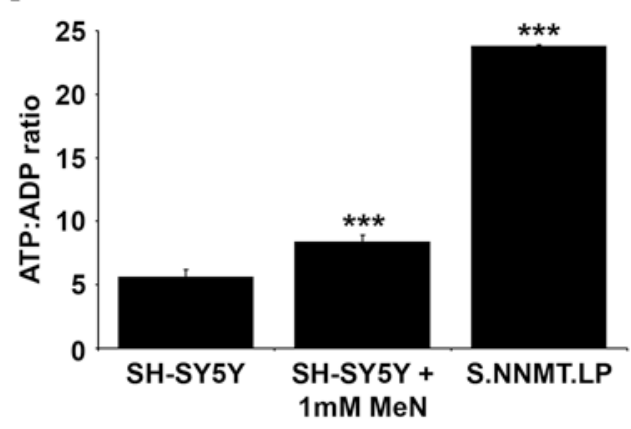

C

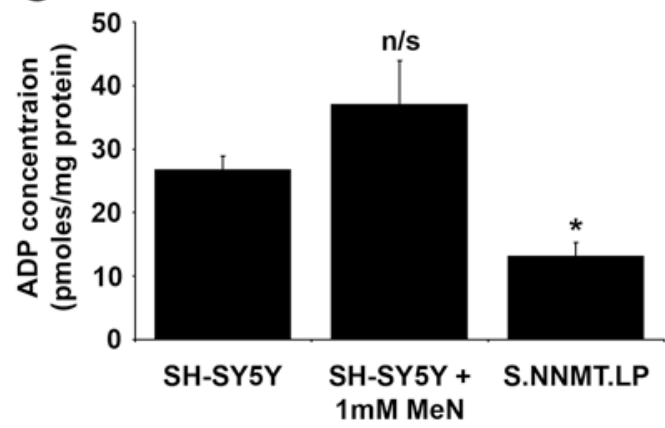

E

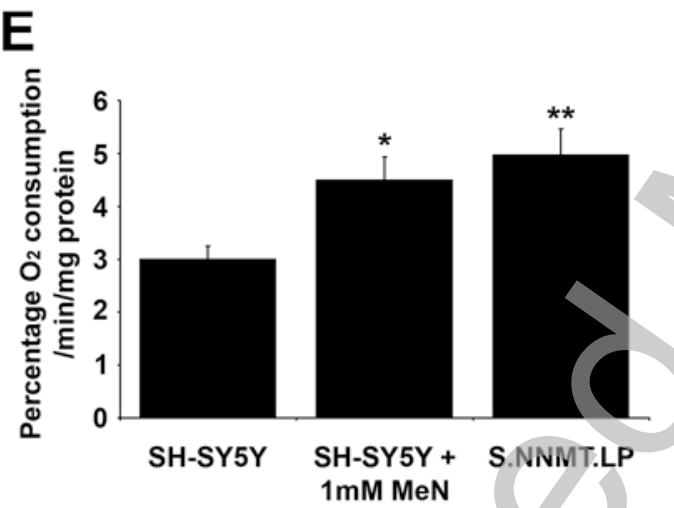

\section{G}

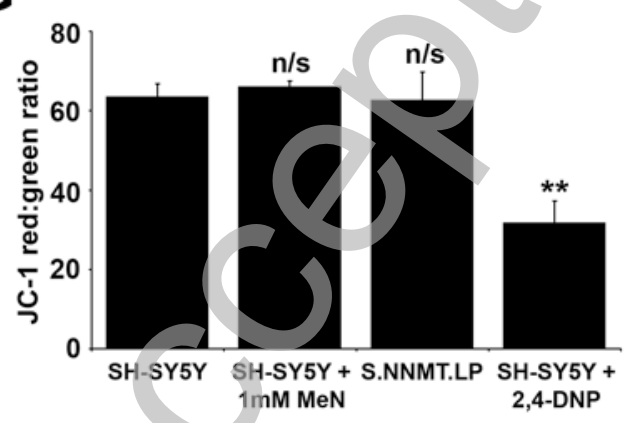

B

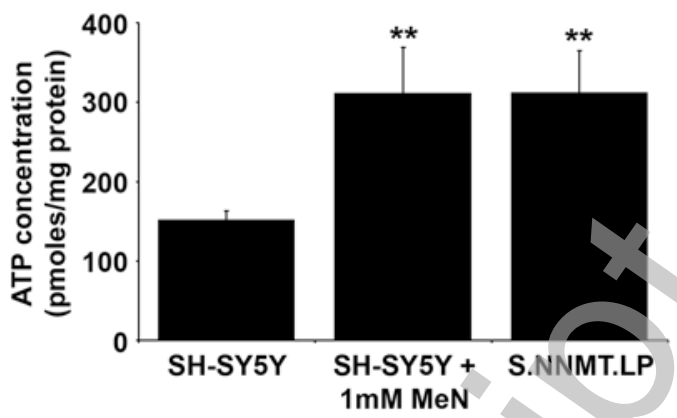

D

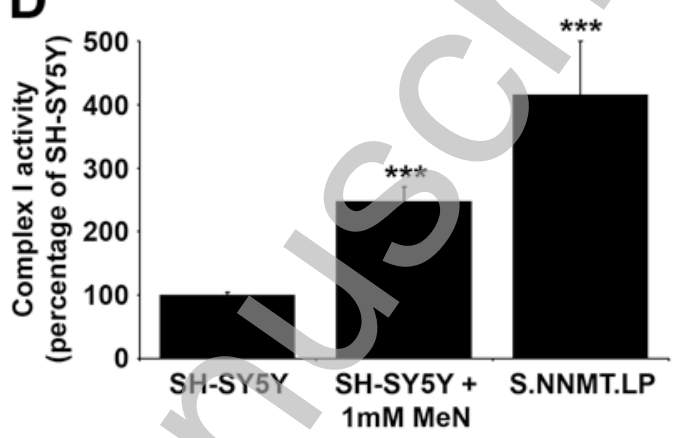

$\mathbf{F}$

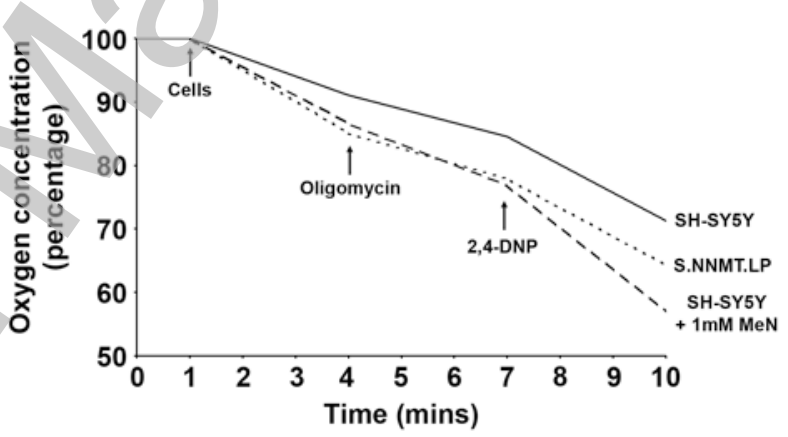

FIGURE 3 
Parsons et al. NNMT expression is cytoprotective via Complex I
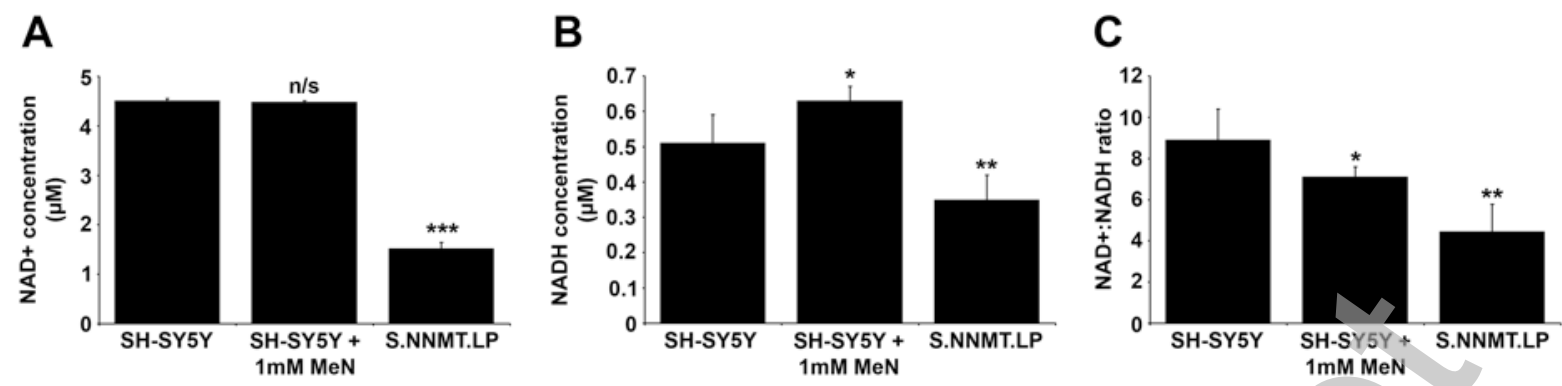

\section{FIGURE 4}


Biochemical Journal Immediate Publication. Published on 25 Feb 2011 as manuscript BJ20101685

Parsons et al. NNMT expression is cytoprotective via Complex I
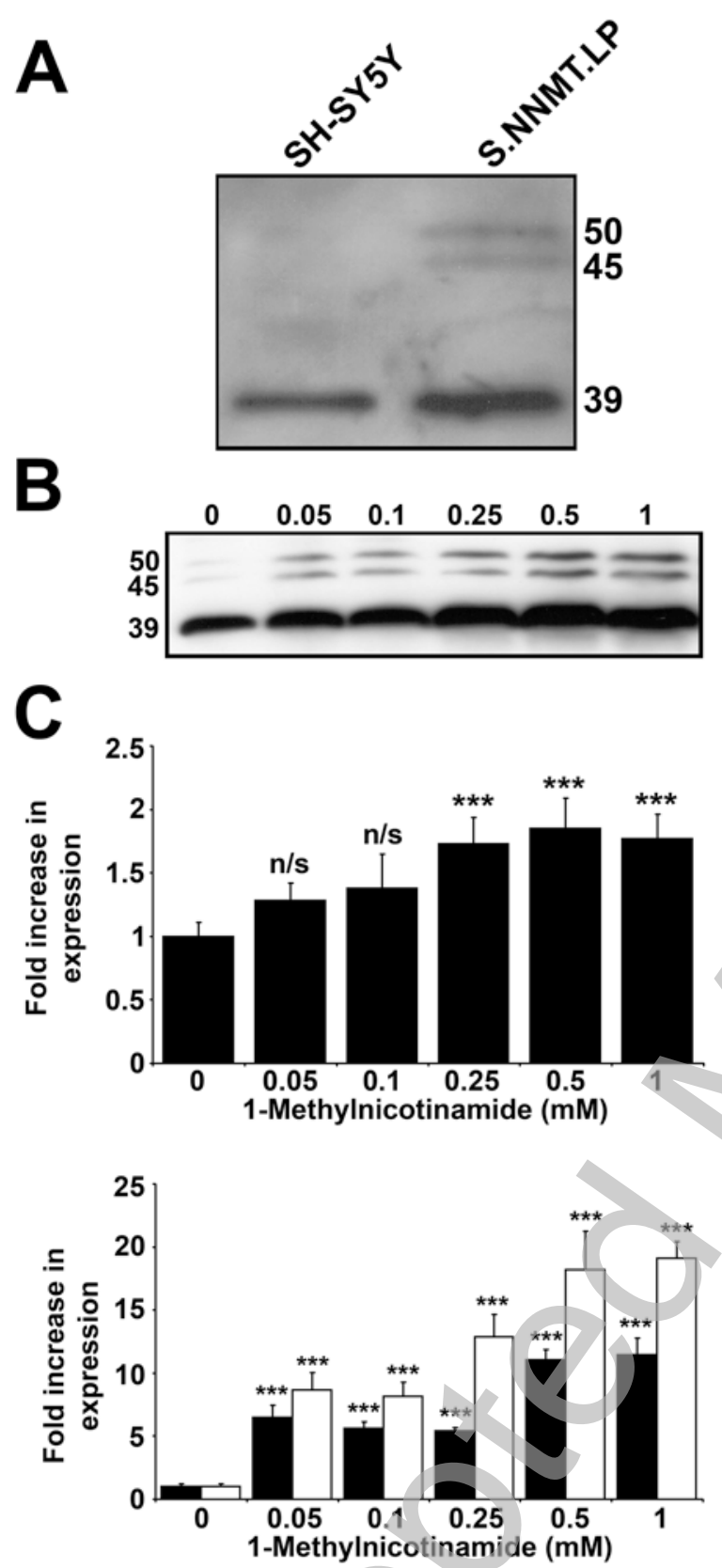

\section{FIGURE 5}


Parsons et al. NNMT expression is cytoprotective via Complex I

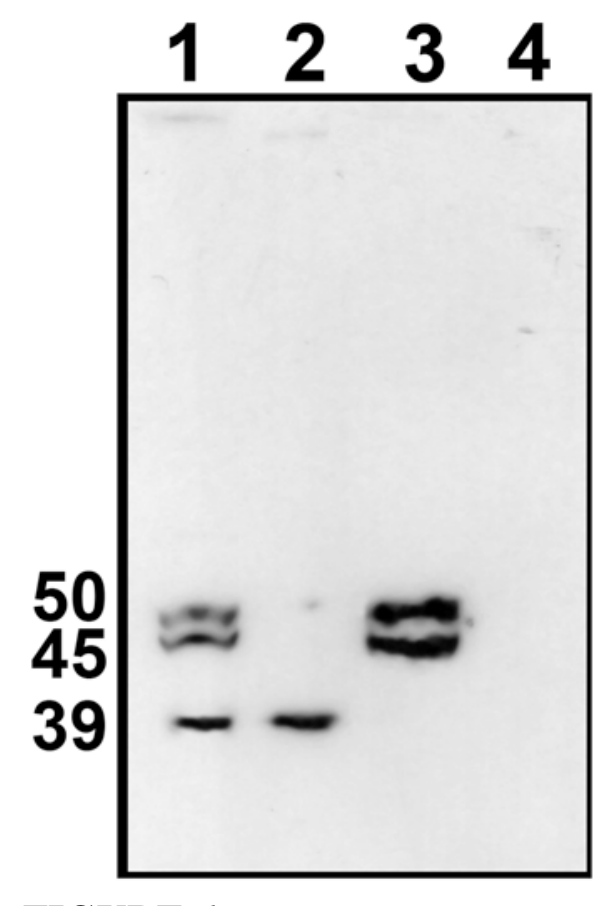

FIGURE 6 
Biochemical Journal Immediate Publication. Published on 25 Feb 2011 as manuscript BJ20101685

Parsons et al. NNMT expression is cytoprotective via Complex I
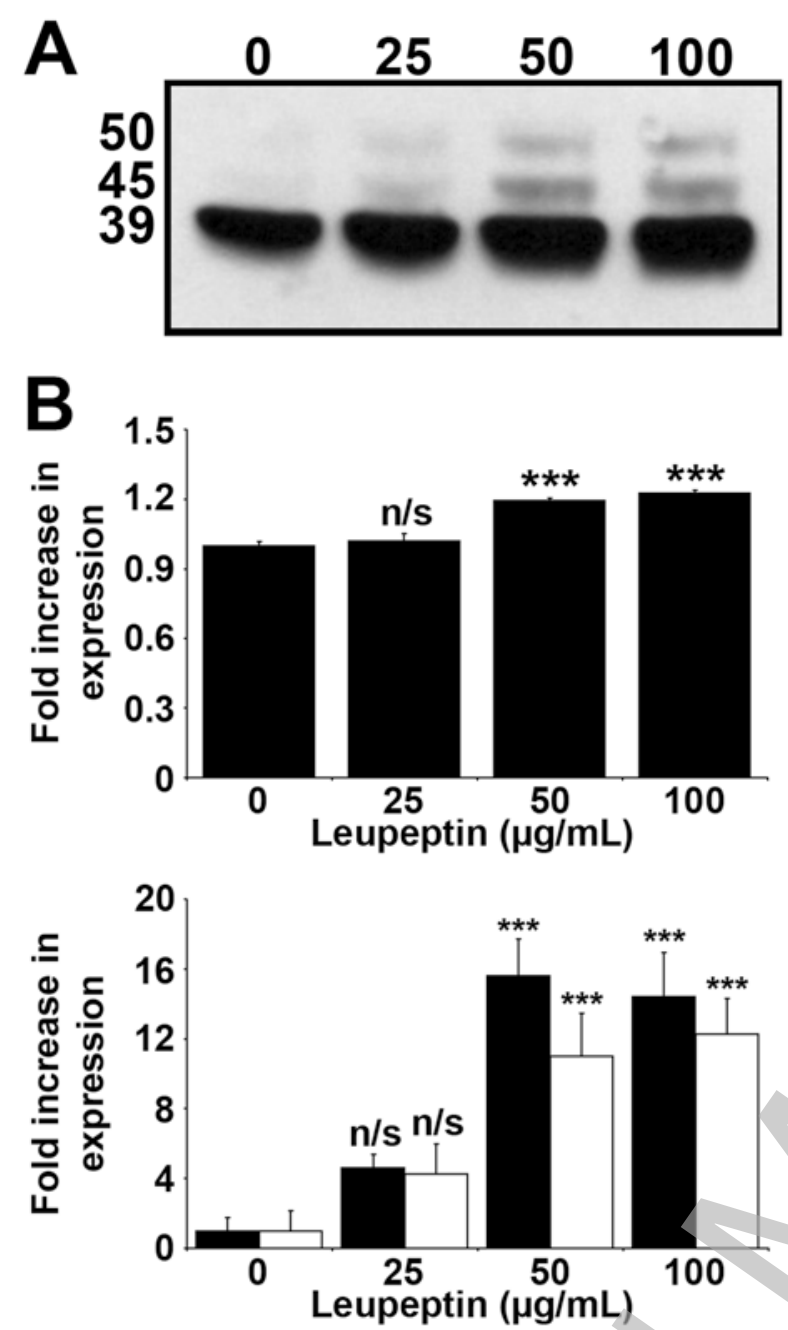

\section{FIGURE 7}


Parsons et al. NNMT expression is cytoprotective via Complex I

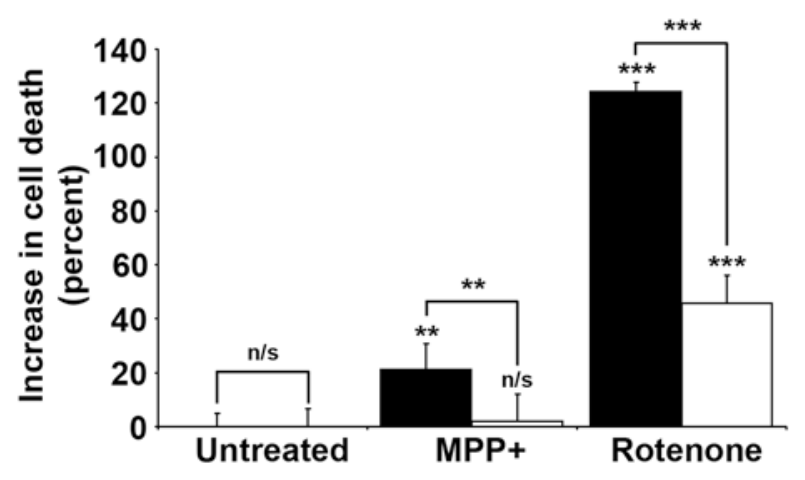

\section{FIGURE 8}


Parsons et al. NNMT expression is cytoprotective via Complex I

A

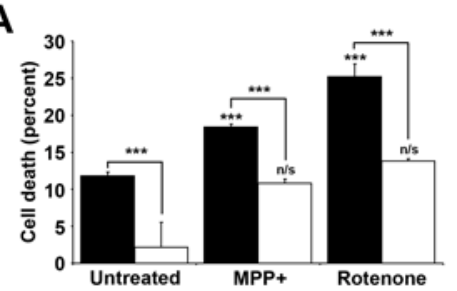

D

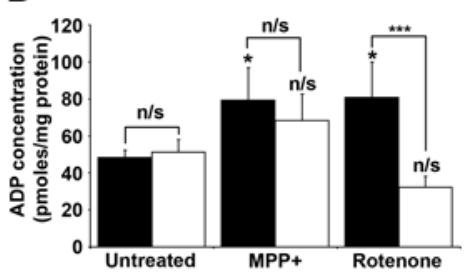

G

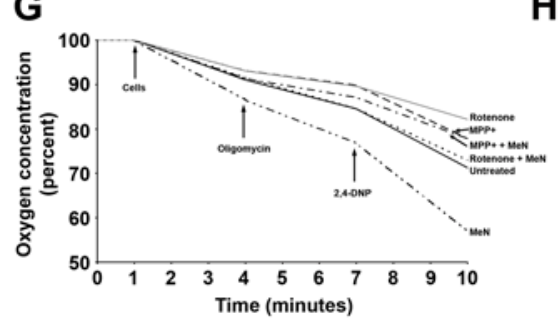

B

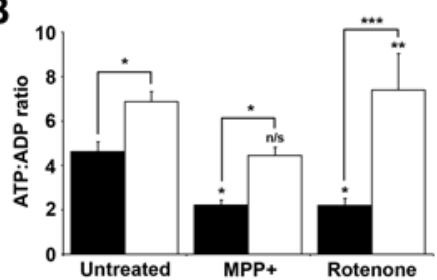

E

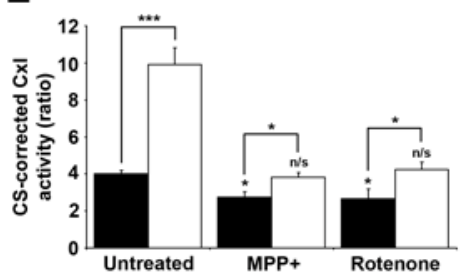

H

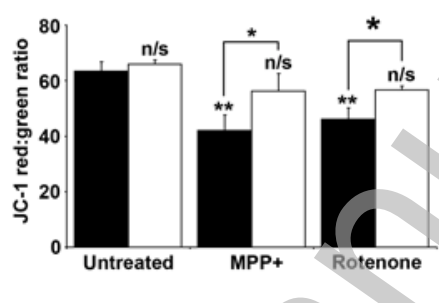

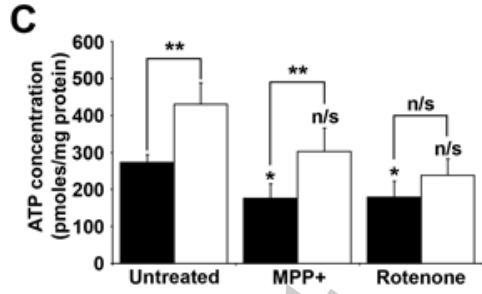

$\mathbf{F}$

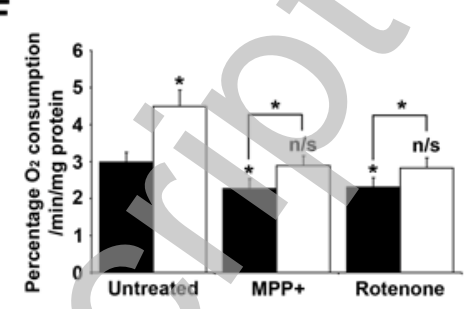

1

\section{FIGURE 9}

